\title{
Use of Non-vitamin K Antagonist Oral Anticoagulants for Stroke Prevention across the Stroke Spectrum: Progress and Prospects
}

\author{
A. John Camm ${ }^{1}$ Dan $\operatorname{Atar}^{2,3}$ \\ ${ }^{1}$ Division of Cardiac and Vascular Sciences, Molecular and Clinical \\ Sciences Research Institute, St George's, University of London, \\ London, United Kingdom \\ 2 Department of Cardiology, Oslo University Hospital Ullevål, Oslo, \\ Norway \\ 3 University of Oslo, Oslo, Norway
}

Thromb Haemost 2021;121:716-730.

\begin{abstract}
Address for correspondence Dan Atar, MD, PhD, Department of Cardiology, Oslo University Hospital Ullevål, Building 3-A, Kirkeveien 166, N - 0450 Oslo, Norway (e-mail: dan.atar@medisin.uio.no).
\end{abstract}

\begin{abstract}
Keywords

- stroke prevention

- non-vitamin $\mathrm{K}$ antagonist oral anticoagulants

- atrial fibrillation

- embolic stroke of undetermined source

- atherosclerosis

Multiple randomized controlled trials and many real-world evidence studies have consistently shown that non-vitamin K antagonist oral anticoagulants (NOACs) are preferable to vitamin $\mathrm{K}$ antagonists for thromboembolic stroke prevention in the majority of patients with atrial fibrillation (AF). However, their role in the management of patients with AF and comorbidities, as well as in other patient populations with a high risk of stroke, such as patients with prior embolic stroke of undetermined source (ESUS) and those with atherosclerosis, is less clear. There is now increasing evidence suggesting that NOACs have a beneficial effect in the prevention of stroke in patients with AF and comorbidities, such as renal impairment and diabetes. In addition, while studies investigating the efficacy and safety of NOACs for the prevention of secondary stroke in patients with a history of ESUS demonstrated neutral results, subanalyses suggested potential benefits in certain subgroups of patients with ESUS. One NOAC, rivaroxaban, has also recently been found to be effective in reducing the risk of stroke in patients with chronic cardiovascular disease including coronary artery disease and peripheral artery disease, further broadening the patient groups that may benefit from NOACs. In this article, we will review recent evidence for the use of NOACs across the stroke spectrum in detail, and discuss the progress and future prospects in the different stroke areas.
\end{abstract}

\section{Introduction}

Stroke is one of the leading causes of mortality and disability worldwide. $^{1,2}$ The majority of strokes are ischemic strokes, which can be further classified based on their etiology: approximately $25 \%$ are associated with large-artery atherosclerosis, $25 \%$ with small artery disease, and $20 \%$ with cardioembolism. ${ }^{3,4}$ Approximately $25 \%$ of ischemic strokes have no definite etiology and are categorized as cryptogenic., ${ }^{4,5}$

The term embolic stroke of undetermined source (ESUS) has been used to describe a subset of cryptogenic stroke that

received

July 16, 2020

accepted after revision

October 31, 2020

published online

January 7, 2021 accounts for approximately $17 \%$ of all ischemic strokes ${ }^{5,6}$ and is diagnosed by excluding other etiologies. ${ }^{4,5}$ ESUS has been defined as a nonlacunar brain infarct without proximal arterial stenosis or cardioembolic sources. ${ }^{4}$ Despite a high risk of stroke recurrence, ${ }^{5}$ there are no specific guidelines in place for secondary prevention in stroke survivors with ESUS. Antiplatelet therapy has been recommended for patients with cryptogenic or non-cardioembolic stroke. ${ }^{7-9}$ Recent studies have evaluated the efficacy and safety of nonvitamin K antagonist oral anticoagulants (NOACs) in patients with ESUS. ${ }^{10,11}$
DOI https://doi.org/ 10.1055/s-0040-1721665. ISSN 0340-6245.
Georg Thieme Verlag KG,

Rüdigerstraße 14,

70469 Stuttgart, Germany 
The majority of cardioembolic strokes are precipitated by atrial fibrillation (AF), ${ }^{12}$ which is the most common sustained cardiac arrhythmia. ${ }^{13} \mathrm{AF}$ increases the risk of stroke by approximately fivefold. ${ }^{14}$ To reduce the risk of stroke in patients with AF, current guidelines recommend the use of NOACs and vitamin K antagonists (VKAs), with a preference for NOACs in most patients. ${ }^{15,16}$ While the use of NOACs for stroke prevention in patients with $\mathrm{AF}$ is well established, their use in the management of patients with AF and comorbidities is less well studied.

Atherosclerotic vascular disease is a leading cause of ischemic stroke. ${ }^{4,17}$ Patients with previous atherothrombotic events and/or chronic cardiovascular (CV) disease have an increased risk of recurrent CV events, which underlines the importance of secondary prevention in these patients. ${ }^{17,18}$ While antiplatelet therapy is the current standard of care in the prevention of CV events among patients with atherosclerotic disease, ${ }^{18-21}$ combinations of antiplatelet agents and anticoagulants have also been studied in patients with acute ${ }^{22-26}$ and chronic CV disease. ${ }^{27}$

Recent years have seen exciting new data on the use of NOACs for the prevention of cardioembolic stroke in patients with AF, recurrent stroke in patients with ESUS, and ischemic stroke in patients with chronic CV disease. This review aims to summarize these new data, their clinical implications, and discuss future prospects in these areas.

\section{What Is New in Stroke Prevention in Patients with Atrial Fibrillation?}

While reducing the risk of stroke remains the priority in patients with $\mathrm{AF}$, it is important to consider all elements of patient protection, including minimizing the risk of bleeding and preserving renal function, when anticoagulating these patients. The majority of patients with AF have comorbidities, such as diabetes and renal disease, which have been shown to increase the risk of stroke, ${ }^{13,28}$ and need to be taken into account when making treatment decisions.

\section{NOACs in Patients with Atrial Fibrillation}

The efficacy and safety of NOACs in the prevention of ischemic stroke in patients with AF have been demonstrated in the four pivotal phase III trials ARISTOTLE, ENGAGE AF-TIMI 48, RE-LY, and ROCKET AF, and a large meta-analysis comparing NOACs with warfarin. ${ }^{29-33}$ NOACs were found to be either equally or more effective than warfarin in reducing the risk of stroke in patients with $\mathrm{AF}$, and were associated with significant reductions in intracranial hemorrhage ( $\mathrm{ICH}$ ) and mortality, with similar rates of major bleeding. ${ }^{29-33}$ However, except for apixaban, NOACs were shown to increase the rate of gastrointestinal bleeding by approximately $25 \%$ compared with warfarin. ${ }^{33}$ It should be noted that the baseline stroke and bleeding risk of patients in the trials differed substantially, with ROCKET AF recruiting the highest proportion of patients with a $\mathrm{CHADS}_{2}$ score $\geq 3$. The findings of the four phase III trials are further supported by various real-world studies, ${ }^{34-37}$ including a recent meta-analysis which also suggested a potential difference in stroke risk reduction between the different NOACs. ${ }^{36}$ In this meta-analysis, rivaroxaban and dabigatran, but not apixaban, were associated with a significantly lower risk of ischemic stroke versus VKAs. ${ }^{36}$ The risk of major bleeding was similar for rivaroxaban and VKAs, and lower for dabigatran or apixaban compared with VKAs. ${ }^{36}$ However, many studies included in the analysis did not report the dose of NOAC used and, given that the analysis considers real-world data, the inevitable selection biases limit the ability to draw conclusions. ${ }^{36}$ Inappropriate dosing has been shown to impact the effectiveness of NOACs, ${ }^{38}$ and will be discussed later in more detail.

\section{Renal Function}

Renal function is an important aspect to consider when using anticoagulant therapy in patients with AF (-Fig. 1). ${ }^{16,39}$ Several factors, including AF itself, older age, hypertension, and comorbidities such as diabetes, can increase the risk of renal impairment. ${ }^{40}$ Impairment of renal function has been associated with not only an increased risk of thromboembolic events but also an increased rate of bleeding. ${ }^{28,41}$ In addition, because all four NOACs are partially eliminated via the kidneys, dose reductions are necessary to avoid drug accumulation in patients with renal impairment. ${ }^{16}$ Therefore, guidelines recommend assessing renal function in patients with AF at treatment initiation and at least yearly thereafter to select the appropriate dose. ${ }^{15,16}$ If renal function worsens, renal function testing is required more frequently and dosages might need to be adjusted, in line with label recommendations. ${ }^{15,16,42}$

Prespecified subgroup analyses of the phase III trials of NOACs in AF and a large meta-analysis of these trials demonstrated that the relative efficacy and safety of NOACs versus warfarin was maintained in patients with AF and mild-tomoderately impaired renal function ( - Table 1). ${ }^{33,43-46}$

In the meta-analysis, NOACs versus warfarin reduced the risk of stroke or systemic embolism (SE) by $21 \%$ in patients with creatinine clearance $(\mathrm{CrCl})<50 \mathrm{~mL} / \mathrm{min}$ (hazard ratio [HR]: $0.79,95 \%$ confidence interval $[\mathrm{CI}]: 0.65-0.96)$ and by $25 \%$ in patients with $\mathrm{CrCl}$ of 50 to $80 \mathrm{~mL} / \mathrm{min}$ (HR: 0.75 , 95\% CI: 0.66-0.85). ${ }^{33}$ Major bleeding events were similar for NOACs and warfarin in patients with $\mathrm{CrCl}<50 \mathrm{~mL} / \mathrm{min}$ (HR: $0.74,95 \% \mathrm{CI}: 0.52-1.05)$ and those with $\mathrm{CrCl}$ of 50 to $80 \mathrm{~mL} /$ min (HR: 0.91, 95\% CI: 0.76-1.08). ${ }^{33}$

Real-world evidence (RWE) supports the favorable benefitrisk profile of NOACs versus warfarin ${ }^{47,48}$ or phenprocoumon ${ }^{49,50}$ in patients with $\mathrm{AF}$ and renal impairment seen in phase III trials. There is only limited evidence for the use of NOACs in patients with AF and advanced chronic kidney disease (CKD) or end-stage renal disease. Patients with an estimated glomerular filtration rate (eGFR) $<25-30 \mathrm{~mL} / \mathrm{min}$ were excluded from all randomized trials comparing NOACs with warfarin ${ }^{29-32}$ and RWE studies have reported conflicting safety results. ${ }^{51-56}$ Currently, the Food and Drug Administration provides guidance for the use of apixaban and rivaroxaban, but not dabigatran or edoxaban, in patients with endstage renal disease on dialysis, which are based on pharmacokinetic studies and limited real-world data. ${ }^{57-60}$ Results of the randomized trial RENAL-AF, which was stopped early due to 


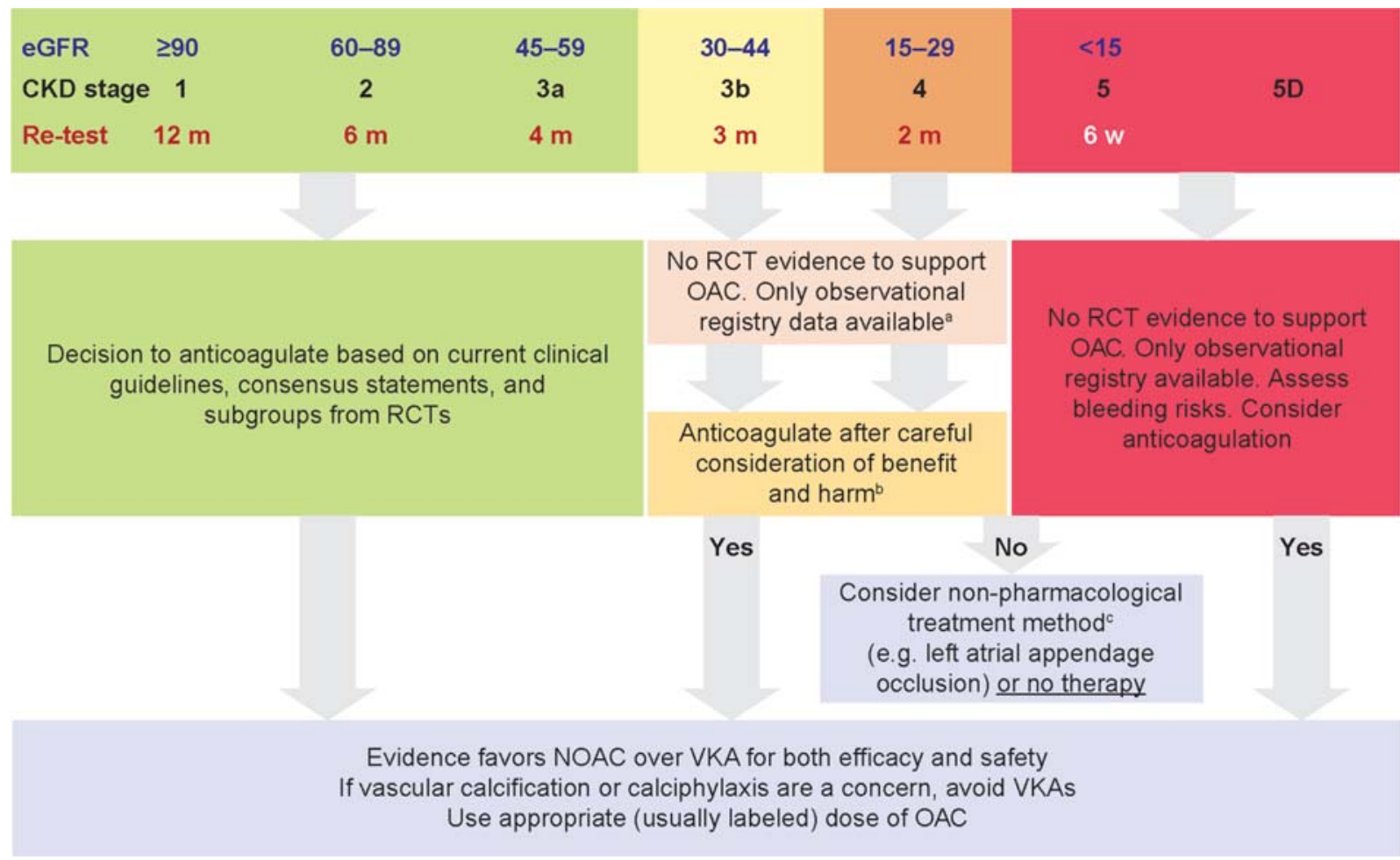

Fig. 1 Algorithm for the management of patients with non-valvular AF and CKD. CKD stage is defined in terms of ranges of the eGFR. Re-testing of renal function depends on the stage of renal function and the eGFR. RCT evidence for favorable effects of oral anticoagulation (VKAs or NOACs) is much less certain as renal function declines. ${ }^{16}$ (Figure adapted from Kumar et al ${ }^{39}$.) AF, atrial fibrillation; CKD, chronic kidney disease; $\mathrm{CrCl}$, creatinine clearance; eGFR, estimated glomerular filtration rate; NOAC, non-vitamin K oral anticoagulant; OAC, oral anticoagulant; RCT,

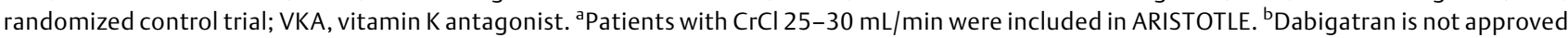
in Europe for use in patients with severe renal impairment $(\mathrm{CrCl}<30 \mathrm{~mL} / \mathrm{min})$. ' Limited data are available from subgroups of registries.

Table 1 Overview of results from prespecified subanalyses of phase III studies of NOACs for stroke prevention

\begin{tabular}{|c|c|c|c|c|}
\hline Study $(N)$ & Patients $(n)$ & Treatment arms & $\begin{array}{l}\text { Primary outcome: } \\
\text { stroke/SE: ARR (\%) }\end{array}$ & $\begin{array}{l}\text { Primary outcome: } \\
\text { stroke/SE: NNT }\end{array}$ \\
\hline \multicolumn{5}{|c|}{ Moderate renal impairment $(\mathrm{CrCl} \leq 50 \mathrm{~mL} / \mathrm{min})$} \\
\hline $\begin{array}{l}\text { ROCKET AF } \\
(14,264)\end{array}$ & 2,950 & Rivaroxaban 15 mg once daily vs. warfarin & 0.45 & 223 \\
\hline \multirow{2}{*}{$\begin{array}{l}\text { RE-LY44,b } \\
(18,113)\end{array}$} & \multirow[t]{2}{*}{3,554} & Dabigatran 150 mg twice daily vs. warfarin & 1.17 & 86 \\
\hline & & Dabigatran $110 \mathrm{mg}$ twice daily vs. warfarin & 0.38 & 264 \\
\hline $\begin{array}{l}\text { ARISTOTLE }^{31,45} \\
(18,201)\end{array}$ & 3,017 & $\begin{array}{l}\text { Apixaban } 5 \mathrm{mg} \text { or } 2.5 \mathrm{mg} \text { twice } \\
\text { daily vs. warfarin }\end{array}$ & 0.56 & 179 \\
\hline $\begin{array}{l}\text { ENGAGE AF-TIMI } 48^{46} \\
(21,105)\end{array}$ & 2,740 & Edoxaban $30 \mathrm{mg}$ once daily vs. warfarin & 0.40 & 250 \\
\hline \multicolumn{5}{|l|}{ Diabetes } \\
\hline $\begin{array}{l}\text { ROCKET AF } \\
(14,264)\end{array}$ & 5,695 & $\begin{array}{l}\text { Rivaroxaban } 20 \mathrm{mg} \text { or } 15 \mathrm{mg} \text { once } \\
\text { daily vs. warfarin }\end{array}$ & 0.40 & 250 \\
\hline \multirow{2}{*}{$\begin{array}{l}\text { RE-LY103,b } \\
(18,133)\end{array}$} & \multirow[t]{2}{*}{4,221} & Dabigatran 150 mg twice daily vs. warfarin & 0.89 & 113 \\
\hline & & Dabigatran 110 mg twice daily vs. warfarin & 0.59 & 170 \\
\hline $\begin{array}{l}\text { ARISTOTLE }^{102} \\
(18,201)\end{array}$ & 4,547 & $\begin{array}{l}\text { Apixaban } 5 \mathrm{mg} \text { or } 2.5 \mathrm{mg} \text { twice } \\
\text { daily vs. warfarin }\end{array}$ & 0.47 & 213 \\
\hline $\begin{array}{l}\text { ENGAGE AF-TIMI } 48^{105} \\
(21,105)\end{array}$ & 7,624 & $\begin{array}{l}\text { Edoxaban } 60 \mathrm{mg} \text { or } 30 \mathrm{mg} \text { once } \\
\text { daily vs. warfarin }\end{array}$ & 0.10 & 1,000 \\
\hline
\end{tabular}

Abbreviations: ARR, absolute risk reduction; $\mathrm{CrCl}$, creatinine clearance; eGFR, estimated glomerular filtration rate; NNT, number needed to treat; NOAC, non-vitamin K antagonist oral anticoagulant; SE, systemic embolism.

${ }^{a}$ The NNT refers to the number of patients who need to receive treatment with a NOAC to prevent one additional bad outcome.

batients receiving dabigatran in the RE-LY study were randomized to receive dabigatran $150 \mathrm{mg}$ twice daily or dabigatran $110 \mathrm{mg}$ twice daily in a blinded fashion, regardless of baseline renal function. ${ }^{44}$ 
loss of funding, were recently presented at the American Heart Association congress 2019.61 After 1-year follow-up, apixaban $5 \mathrm{mg}$ twice daily was associated with similar rates of bleeding and stroke as warfarin among patients with end-stage renal disease on dialysis. ${ }^{60}$ The randomized trials AXADIA and SAFE-HD, which are ongoing, will provide more clarity on the treatment effect of NOACs versus VKAs in patients with severe renal disease. ${ }^{62,63}$

Renal function decline is commonly observed in patients with $\mathrm{AF}$ treated with oral anticoagulants ${ }^{42}$ and has been either linked to vascular calcification or anticoagulant-related nephropathy (ARN). ${ }^{64-66}$ Anticoagulant-associated worsening of renal function may be caused by renovascular calcification. ${ }^{66}$ Evidence suggests that vascular calcification is linked to VKAs but not NOACs ( $\mathbf{- F i g . ~ 2 A )})^{64,67}$ ARN is a form of acute kidney injury (AKI) caused by excessive anticoagulation. ${ }^{64,65}$ Repeated episodes of AKI may accelerate CKD progression. ${ }^{68}$ ARN has originally been described in patients who received overdoses of warfarin, but it has also been reported occasionally in patients treated with NOACs. ${ }^{64,65,69}$ Potential underlying molecular mechanisms have been suggested for the roles of warfarin or dabigatran in ARN, including thrombin depletion, reductions in activated protein C, and inhibition of factor VII (-Fig. 2B) ${ }^{64,70,71}$ Although there is growing evidence that ARN is a potentially serious complication of anticoagulation, the mechanisms are still poorly understood and the true incidence of NOAC-related nephropathy is yet to be determined in clinical studies. ${ }^{64,72,73}$

Several real-world studies suggest that NOACs may be associated with better preservation of renal function than warfarin in routine clinical practice (-Fig. 3). ${ }^{42,50,74-81}$ In a large U.S. administrative database analysis, NOACs, in particular rivaroxaban and dabigatran, were associated with lower risks of renal decline compared with warfarin. ${ }^{41}$ Cohort studies in Taiwan also suggested a lower risk of AKI for apixaban, dabigatran, and rivaroxaban compared with warfarin in patients with and without a history of CKD, ${ }^{75,76}$ which was also observed in an administrative health care database analysis in Quebec, Canada. ${ }^{77}$ In a large U.S. cohort study that analyzed the risk of AKI with NOACs across the spectrum of eGFR, apixaban, dabigatran, and rivaroxaban were associated with a $28 \%$ risk reduction of AKI versus warfarin in patients with relatively preserved renal function $\left(\right.$ eGFR $\left.\geq 60 \mathrm{~mL} / \mathrm{min} / 1.73 \mathrm{~m}^{2}\right) .{ }^{74}$ In patients with an eGFR of 30 to $59 \mathrm{~mL} / \mathrm{min} / 1.73 \mathrm{~m}^{2}$, only dabigatran reduced the risk of AKI compared with warfarin. ${ }^{74}$ Evidence for the potential nephroprotective effect of NOACs has been derived from real-world studies with rivaroxaban. The RIVAL study, a retrospective claims analysis using U.S. Truven MarketScan data, suggested that patients receiving rivaroxaban are less likely to develop AKI and progress to stage 5 CKD or need hemodialysis than those receiving warfarin. ${ }^{78}$ Recent results from the retrospective database analyses RELOADED and CALLIPER further support the nephroprotective effect of rivaroxaban. ${ }^{50,80}$ The ongoing multicenter registry XARENO will provide more information on renal outcomes in patients with $\mathrm{AF}$ and renal impairment receiving rivaroxaban for stroke prevention. ${ }^{81}$ In this study, patients with moderate- to-severe renal impairment (eGFR $15-49 \mathrm{~mL} / \mathrm{min} / 1.73 \mathrm{~m}^{2}$ ) are allocated to treatment with rivaroxaban, VKA, or no treatment, and are prospectively followed for an estimated mean duration of 18 months to assess changes in renal function and clinical outcomes. ${ }^{82}$

The findings from the clinical trials and RWE studies are also acknowledged in an update to the American College of Cardiology/American Heart Association/Heart Rhythm Society guidelines on the management of AF, which state that "Over time, NOACs (particularly dabigatran and rivaroxaban) may be associated with a lower risk of adverse renal outcomes than warfarin in patients with AF." ${ }^{83}$ Taken together, the totality of evidence supports the need to minimize renal function decline in patients with AF treated with oral anticoagulants.

\section{Diabetes and Atrial Fibrillation}

Diabetes, renal function, and CV risk are closely interlinked. Diabetes is a common comorbidity in patients with $\mathrm{AF}$, and its presence is associated with an increased risk of developing $\mathrm{AF}^{13,84}$ Diabetes is also an independent risk factor for $\mathrm{CV}$ disease and has been shown to increase the risk of stroke and thromboembolism in patients with AF through several different mechanisms (-Fig. 4). ${ }^{85-91}$ In addition, type 2 diabetes is the leading cause of renal failure in the developed world, ${ }^{92}$ with moderate-to-severe kidney disease estimated to be found in 15 to $27 \%$ of patients with diabetes. ${ }^{93-95}$ Renal function decline in diabetes may be due to protease-activated receptorinduced inflammatory nephropathy ( $\mathbf{F i g . ~ 2 C )}{ }^{96-100}$

Importantly, the combination of diabetes and renal impairment is associated with a higher risk of $\mathrm{CV}$ events and mortality than either comorbidity alone, ${ }^{93,101}$ underlining the importance of $\mathrm{CV}$ prevention in these particularly vulnerable patients.

Evidence suggests that NOACs are an effective treatment option in stroke prevention in patients with $\mathrm{AF}$ and diabetes. $^{33,89,102-105}$ Subgroup analyses of the phase III trials and meta-analyses of these trials demonstrated that NOACs were at least as effective as warfarin in reducing the risk of stroke and offer a similar safety profile in patients with $\mathrm{AF}$ and diabetes ( $\mathbf{- T a b l e ~ 1 ) . ~}{ }^{33,89,102-105}$ A subanalysis of patients with diabetes in the ARISTOTLE trial found that apixaban was associated with a $25 \%$ risk reduction of stroke/SE (HR: $0.75,95 \%$ CI: $0.53-1.05$ ) and an $11 \%$ risk reduction of CV death (HR: 0.89, 95\% CI: 0.66-1.20) compared with warfarin. ${ }^{102}$ Major bleeding rates were similar for apixaban and warfarin in patients with diabetes. ${ }^{102}$ In a subanalysis of patients with diabetes in RE-LY, dabigatran $150 \mathrm{mg}$ and dabigatran $110 \mathrm{mg}$ were associated with 39\% (HR: $0.61,95 \% \mathrm{CI}$ : $0.41-0.91$ ) and $26 \%$ (HR: $0.74,95 \% \mathrm{CI}: 0.51-1.07$ ) reductions in the risk of stroke/SE and $14 \%$ (HR: $0.86,95 \% \mathrm{CI}: 0.65-1.13$ ) and 19\% (HR: 0.81 , 95\% CI: 0.62-1.07) reductions in the risk of CV death, respectively. ${ }^{102}$ The risk of major bleeding was similar for both doses of dabigatran versus warfarin. ${ }^{103}$ In the prespecified subanalysis of ROCKET AF, rivaroxaban resulted in an $18 \%$ risk reduction of stroke/SE (HR: 0.82, 95\% CI: 0.63-1.08) and a $20 \%$ risk reduction of $\mathrm{CV}$ death (HR: $0.80,95 \% \mathrm{CI}$ : 0.64-0.99) compared with warfarin, with no difference in the risk of major bleeding. In the subanalysis of ENGAGE AF-TIMI 48 
A

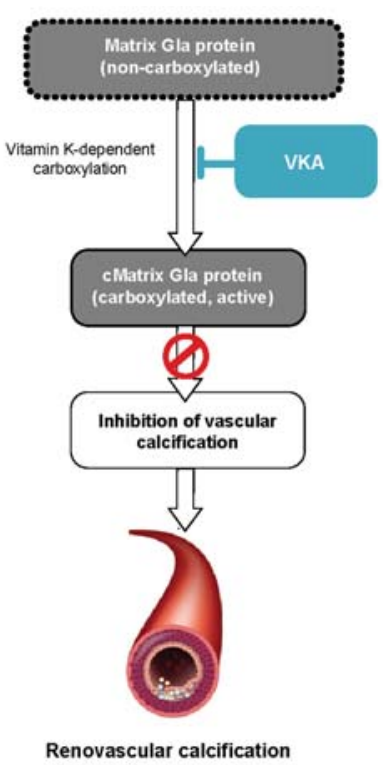

B

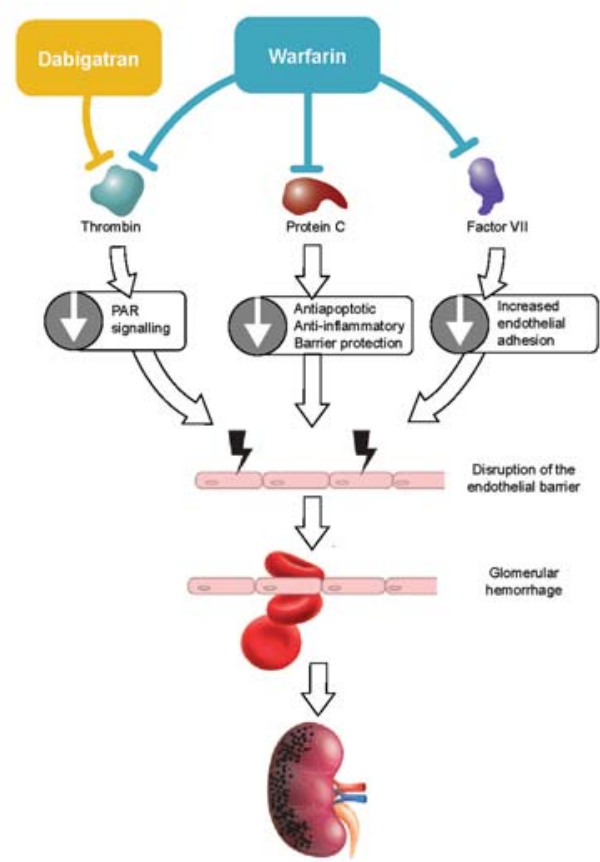

Acute kidney injury

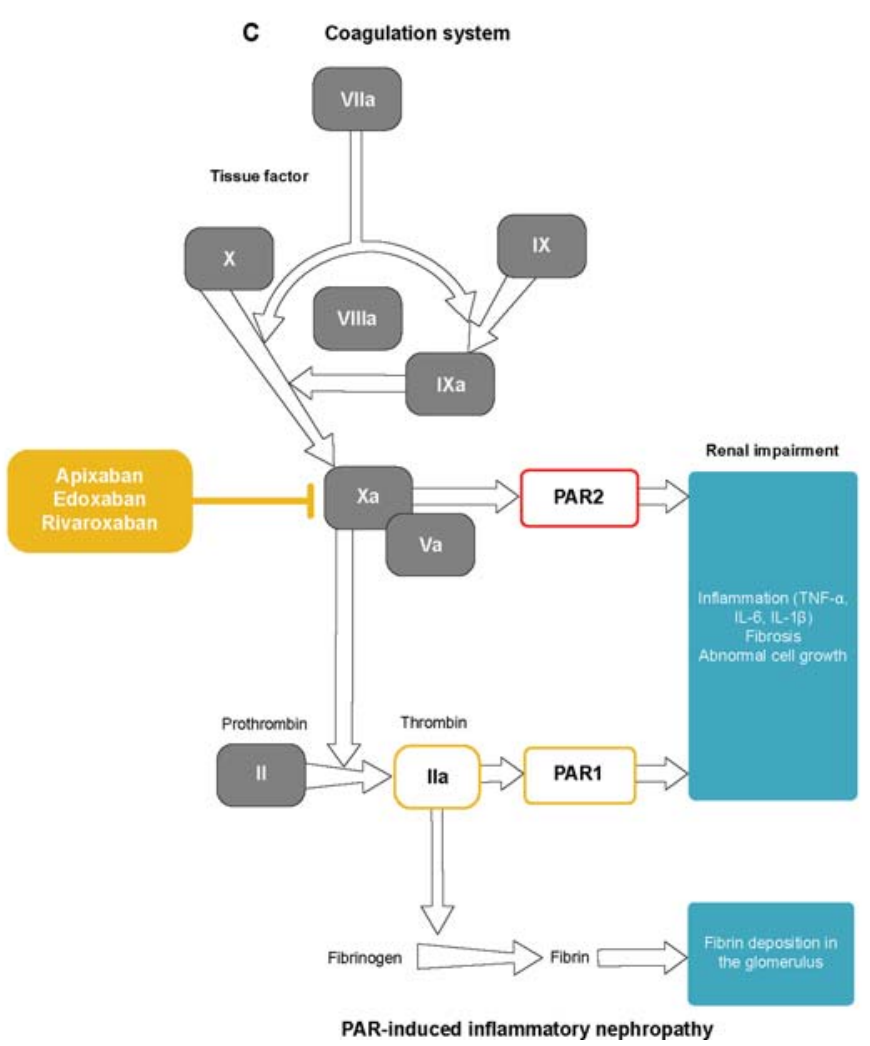

Fig. 2 Potential mechanisms underlying renovascular calcification ${ }^{64}(A)$, anticoagulation-related nephropathy (B) ${ }^{71}$ and diabetic inflammatory nephropathy (C). ${ }^{95-99}$ IL-1 $\beta$, interleukin $1 \beta$; IL-6, interleukin-6; PAR, protease-activated receptor; TNF- $\alpha$, tumor necrosis factor- $\alpha$; VKA, vitamin K antagonist.

in patients with diabetes, high-dose edoxaban $(60 \mathrm{mg}$ once daily) was similarly effective to warfarin in reducing the risk of stroke/SE (HR: $0.93,95 \% \mathrm{CI}: 0.71-1.23$ ) and reduced the risk of major bleeding (HR: 0.79, 95\% CI: 0.65-0.96). ${ }^{105}$

The benefit of NOACs versus VKAs in patients with AF and diabetes seen in phase III trials was further supported by RWE studies (-Fig. 5). ${ }^{50,106,107}$ Large retrospective analyses of U.S. claims data showed that rivaroxaban was equally as effective as warfarin in reducing the risk of stroke/SE ${ }^{106}$ and more effective than warfarin in reducing major adverse $\mathrm{CV}$ events (MACEs) and major adverse limb events, with no difference in major bleeding. ${ }^{107}$ In a retrospective analysis using German 


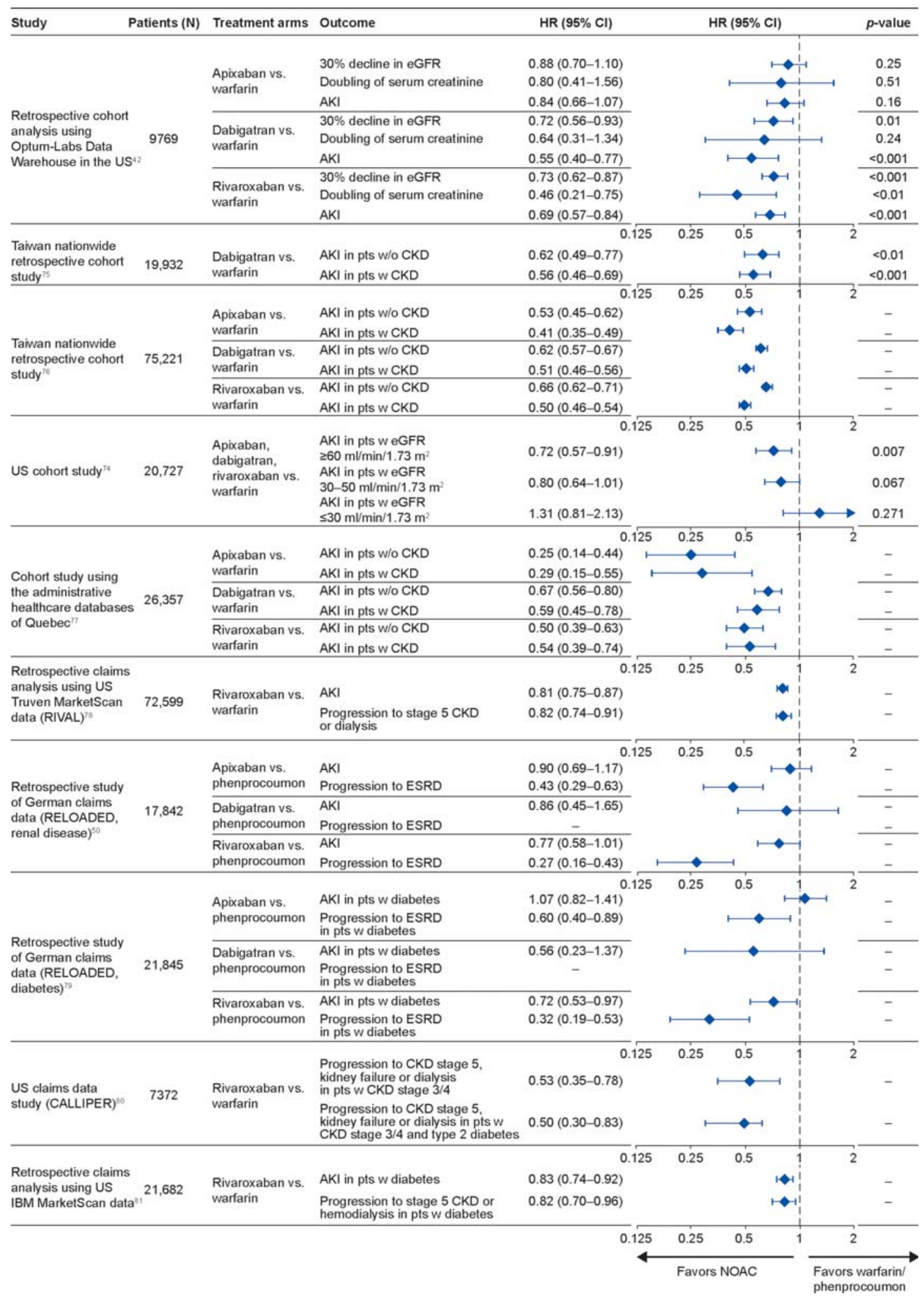

Fig. 3 RWE studies on renal outcomes with NOACs versus VKAs in patients with AF. ${ }^{42,50,74-81}$ AF, atrial fibrillation; AKI, acute kidney injury; Cl, confidence interval; CKD, chronic kidney disease; $\mathrm{CrCl}$, creatinine clearance; eGFR, estimated glomerular filtration rate; $\mathrm{ESRD}$, end-stage renal disease; HR, hazard ratio; NOAC, non-vitamin K antagonist oral anticoagulant; pts, patients; RWE, real-world evidence; VKA, vitamin K antagonist; w, with; w/o, without.

claims data, rivaroxaban, apixaban, and edoxaban were found to have a similar risk of stroke/SE compared with phenprocoumon, and a numerical benefit over phenprocoumon in the risk of $\mathrm{ICH}^{50}$ Considering the high risk of renal impairment in patients with diabetes, studies also investigated the effect of NOACs on renal function in patients with AF and diabetes. In these retrospective database analyses, NOACs were associated with a lower risk of adverse renal events versus 


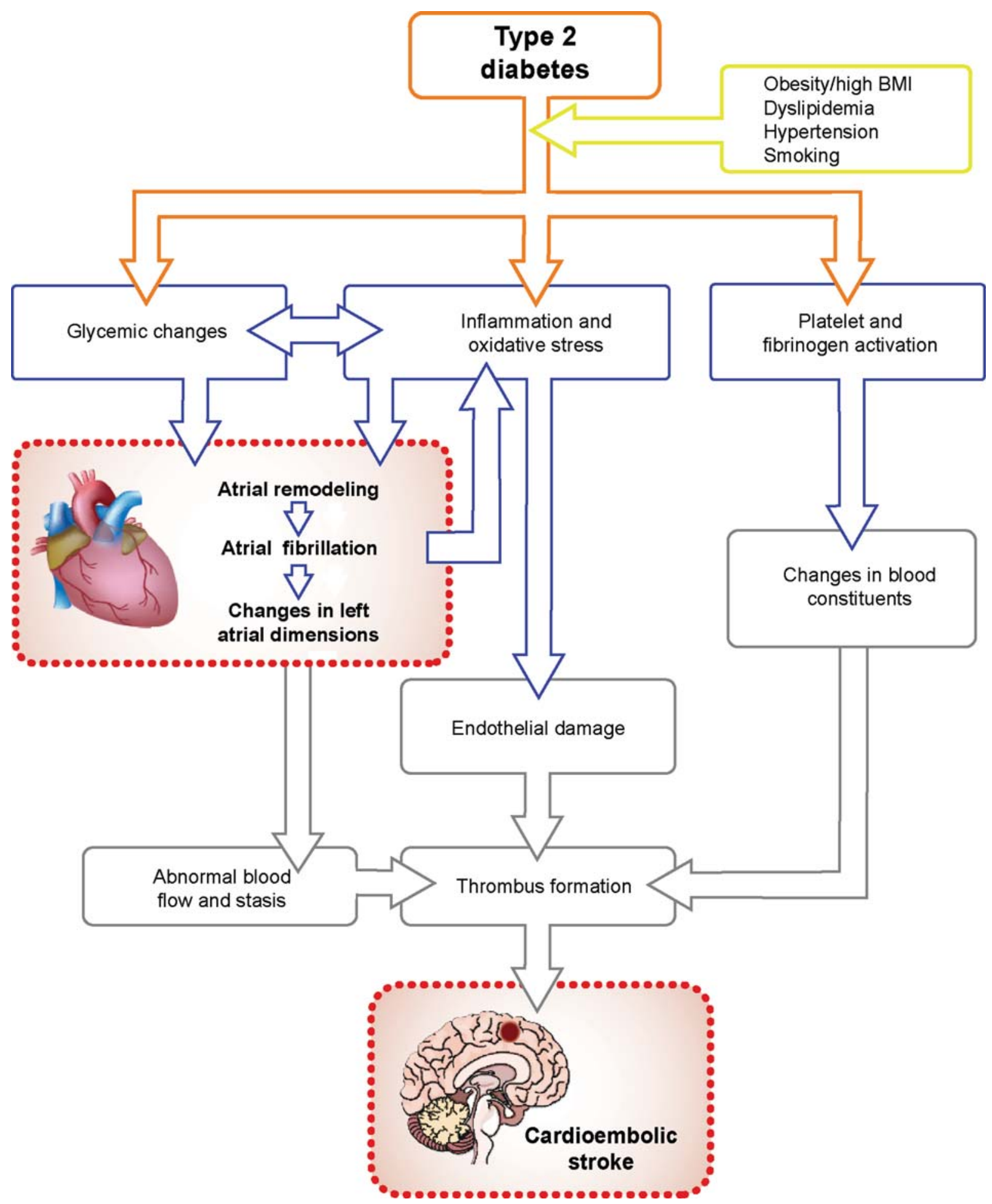

Fig. 4 Possible mechanisms of stroke in patients with type 2 diabetes. ${ }^{89-91}$ BMI, body mass index.

phenprocoumon ${ }^{50}$ or warfarin, ${ }^{81}$ supporting the nephroprotective effect of NOACs in patients with AF and diabetes.

\section{Stroke Risk and NOAC Dosing}

The four phase III trials, ARISTOTLE, ENGAGE AF-TIMI 48, RE$\mathrm{LY}$, and ROCKET AF, also investigated the efficacy and safety of reduced doses of NOACs in patients meeting specific criteria. ${ }^{29-32}$ Dose adjustment of NOACs is recommended in the label for patients with moderate renal impairment, according to the dose reduction criteria investigated in these trials. ${ }^{108-111}$ With regard to apixaban and dabigatran, additional criteria, such as older age and low body weight, need to be met to apply dose reductions. ${ }^{109,110}$ These dose reduction criteria vary slightly depending on the regulatory agency. For example, in the European Union, reduced doses of dabigatran are recommended for patients with moderate renal impairment who are $\geq 80$ years of age and/or receive concomitant verapamil. ${ }^{110}$ In patients with moderate renal 


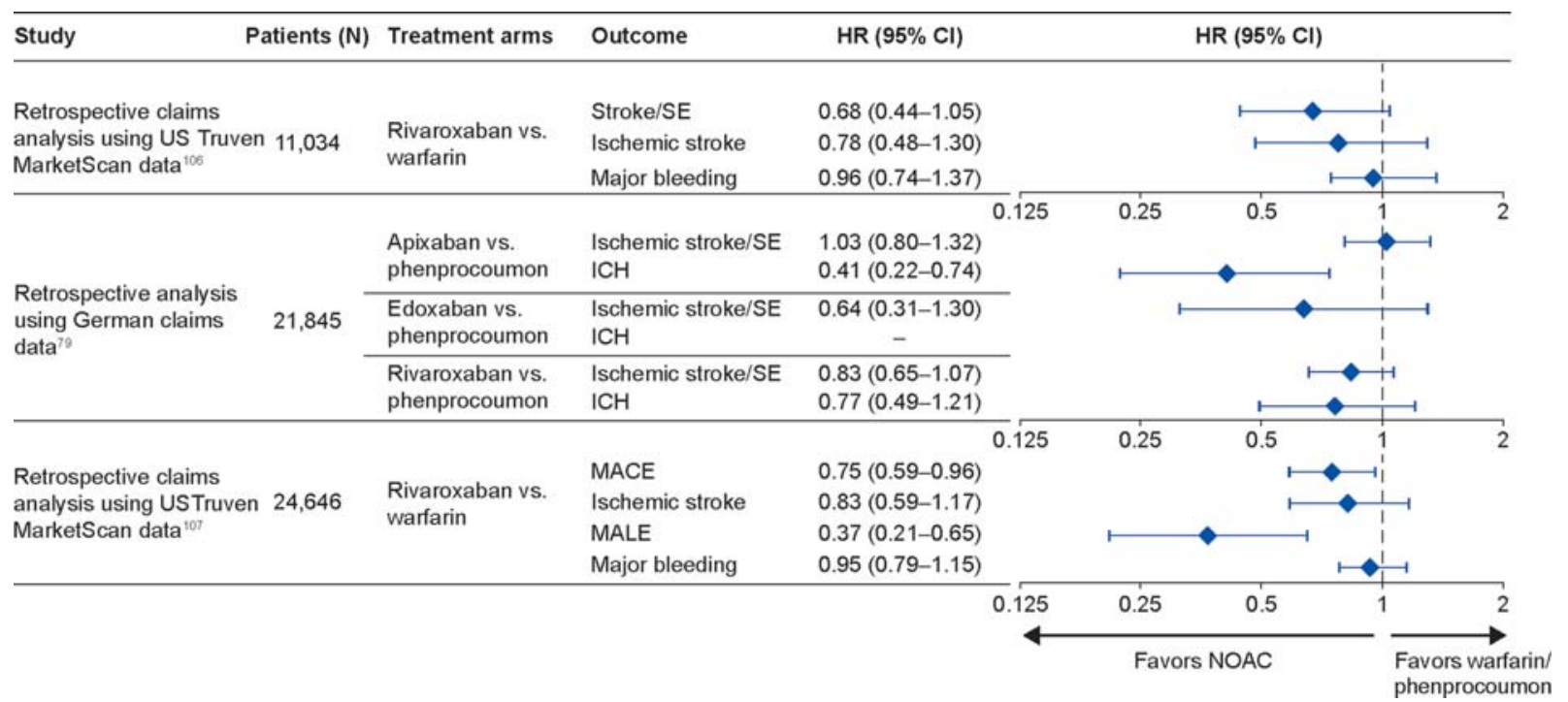

Fig. 5 RWE studies comparing the efficacy and safety of NOACs with VKAs in patients with AF and diabetes. ${ }^{50,106,107}$ AF, atrial fibrillation; $\mathrm{Cl}$, confidence interval; HR, hazard ratio; ICH, intracerebral hemorrhage; MACE, major adverse cardiovascular events; MALE, major adverse limb events; NOAC, non-vitamin K antagonist oral anticoagulant; RWE, real-world evidence; SE, systemic embolism; VKA, vitamin K antagonist.

impairment aged 75-80 years and/or with gastritis, esophagitis, or gastroesophageal reflux, or an increased risk of bleeding, the thromboembolic and bleeding risk will need to be assessed individually to determine the dose. ${ }^{110}$ Dose reductions for apixaban are indicated for patients with moderate renal impairment aged $\geq 80$ years or body weight $\leq 60 \mathrm{~kg} .{ }^{109}$ Reduced doses of edoxaban are not only recommended for renal impairment but also for other single criterion, such as concomitant use of P-glycoprotein inhibitors or body weight $\leq 60 \mathrm{~kg} .{ }^{111}$ Rivaroxaban is the only NOAC for which dose reduction is based solely on renal function. ${ }^{108}$

Adherence to recommended dosing is important, as inappropriate dosing of NOACs has been shown to impact clinical outcomes. ${ }^{38,112-114}$ Patients may receive an inappropriate dose because of lack of adjustments for certain clinical features specified by recommended labeling, such as renal function, weight, or age. This may be because of physician concerns, such as increased risk of bleeding (particularly when assessing complex patients) or the barriers that multiple parameters may represent in determining the correct dose. $^{38,112,113}$ Patient-level factors also contribute to poor adherence and persistence to treatment, such as financial barriers or treatment burden. ${ }^{115}$ Failure to reduce the dose of NOACs in patients with renal disease, in whom it is indicated, may result in an increase in the risk of bleeding; in contrast, inappropriate dose reduction, that is, inconsistent with the label, may decrease the effectiveness of stroke prevention. ${ }^{38}$ Results from a large real-world cohort study demonstrated that lower doses of apixaban in patients with normal or mildly reduced renal function were found to increase the risk of stroke by approximately five times compared with the standard dose. ${ }^{38}$ While RWE for edoxaban is currently limited, it could be speculated that the same reduction in effectiveness might also be true for inappropriate dose reductions of edoxaban because, like apixaban, the reduced dose is half the full dose. No such reductions have been observed for rivaroxaban or dabigatran where the reduced dose is 75 and $73 \%$, respectively, of the full dose.

\section{Studies of NOACs in the Secondary Prevention of ESUS}

Several clinical trials have been initiated to evaluate the efficacy and safety of NOACs for the secondary prevention of stroke in stroke survivors with ESUS (- Table 2). ${ }^{10,11,116,117}$ NAVIGATE ESUS was the first trial that compared a NOAC (rivaroxaban) with aspirin in stroke survivors with a recent history of ESUS. ${ }^{10}$ The trial was terminated prematurely because use of rivaroxaban resulted in higher rates of major bleeding compared with aspirin ( 1.8 vs. $0.7 \%$; HR: $2.72,95 \% \mathrm{CI}$ : $1.68-4.39 ; p<0.001)$, without the benefit of reducing the risk of recurrent stroke/SE (- Fig. 6A). ${ }^{10}$ The RE-SPECT ESUS trial that compared dabigatran with aspirin in ESUS has recently been completed. ${ }^{11}$ Similar to the results of NAVIGATE ESUS, dabigatran did not significantly reduce the risk of recurrent stroke versus aspirin ( - Fig. 6A). ${ }^{11}$ However, a reduction was reported in the risk of disabling stroke with dabigatran compared with aspirin (0.6\% vs. $0.9 \%$; HR: $0.59,95 \% \mathrm{CI}$ : $0.36-0.96)$. Major bleeding rates with dabigatran were similar to those reported for aspirin (1.7 vs. $1.4 \%$; HR: $1.19,95 \% \mathrm{CI}$ : $0.85-1.66),{ }^{11}$ which was much higher than the bleeding rate associated with aspirin in the NAVIGATE ESUS trial. The efficacy and safety of apixaban in secondary stroke prevention in stroke survivors with ESUS are being investigated in the two clinical trials ATTICUS and ARCADIA. ${ }^{116,117}$ A secondary analysis of NAVIGATE ESUS demonstrated that rivaroxaban versus aspirin was associated with a reduced risk of recurrent ischemic stroke in stroke survivors with ESUS with moderate or severe left atrial enlargement (1.7 vs. $6.5 \%$; HR: $0.26,95 \% \mathrm{CI}$ : $0.07-0.94 ; p=0.02) .{ }^{118}$ A subgroup analysis of RE-SPECT ESUS suggested that dabigatran might be effective in reducing the risk of stroke in elderly stroke survivors ( $\geq 75$ years) compared 
Table 2 Overview of completed and ongoing trials of NOACs in ESUS

\begin{tabular}{|c|c|c|c|c|c|}
\hline Study & $\begin{array}{l}\text { Patients } \\
(N)\end{array}$ & Treatment arms & Trial status & Key efficacy outcomes & Key safety outcomes \\
\hline $\begin{array}{l}\text { NAVIGATE } \\
\text { ESUS }^{10}\end{array}$ & 7,213 & $\begin{array}{l}\text { Rivaroxaban } 15 \mathrm{mg} \\
\text { once daily vs. aspirin } \\
100 \text { mg once daily }\end{array}$ & $\begin{array}{l}\text { Terminated } \\
\text { early }\end{array}$ & $\begin{array}{l}\text { - No significant difference } \\
\text { in the risk of recurrent } \\
\text { stroke/SE (HR: } 1.07,95 \% \\
\text { Cl: } 0.87-1.33 ; p=0.52) \\
\text { - ARR: }-0.3 \% \\
\text { - NNT: }-334\end{array}$ & $\begin{array}{l}\text { - Increased risk of } \\
\text { major bleeding with } \\
\text { rivaroxaban } \\
(\mathrm{HR}: 2.72,95 \% \\
\mathrm{Cl}: 1.68-4.39 ; p<0.001)\end{array}$ \\
\hline $\begin{array}{l}\text { RE-SPECT } \\
\text { ESUS }^{11}\end{array}$ & 5,390 & $\begin{array}{l}\text { Dabigatran } 150 \mathrm{mg} \\
\text { twice daily or } \\
110 \mathrm{mg} \text { twice daily } \\
\text { vs. aspirin } 100 \mathrm{mg} \\
\text { once daily }\end{array}$ & Completed & $\begin{array}{l}\text { - No significant difference } \\
\text { in the risk of recurrent } \\
\text { stroke (HR: } 0.85,95 \% \\
\text { CI: } 0.69-1.03 ; p=0.10) \\
\text { - ARR: } 0.7 \% \\
\text { - NNT: } 143\end{array}$ & $\begin{array}{l}\text { - No significant } \\
\text { difference in the risk } \\
\text { of major bleeding } \\
\text { (HR: } 1.19,95 \% \\
\text { Cl: } 0.85-1.66)\end{array}$ \\
\hline ATTICUS $^{116}$ & 500 & $\begin{array}{l}\text { Apixaban } 5 \mathrm{mg} \\
\text { twice daily vs. aspirin } \\
100 \mathrm{mg} \text { once daily }\end{array}$ & Ongoing & Pending & Pending \\
\hline ARCADIA $^{117 c}$ & 1,100 & $\begin{array}{l}\text { Apixaban } 5 \mathrm{mg} \\
\text { twice daily or } \\
2.5 \mathrm{mg} \text { twice daily }{ }^{\mathrm{d}} \mathrm{vs} \text {. } \\
\text { aspirin } 81 \mathrm{mg} \text { once daily }\end{array}$ & Ongoing & Pending & Pending \\
\hline
\end{tabular}

Abbreviations: ARR, absolute risk reduction; $\mathrm{Cl}$, confidence interval; $\mathrm{CrCl}$, creatinine clearance; ESUS, embolic stroke of undetermined source; HR, hazard ratio; NNT, number needed to treat; NOAC, non-vitamin K antagonist oral anticoagulant; SE, systemic embolism.

${ }^{a}$ Due to a lack of benefit in stroke risk reduction and increased bleeding with rivaroxaban.

bower dose of dabigatran for patients aged $\geq 75$ years or with $\mathrm{CrCl} 30-50 \mathrm{~mL} / \mathrm{min}$.

'Populations studied included patients with ESUS and evidence of atrial cardiopathy.

dLower dose of apixaban for patients who have at least two of the following criteria: age $\geq 80$ years, body weight $\leq 60 \mathrm{~kg}$, or $\mathrm{CrCl} \geq 1.5 \mathrm{mg} / \mathrm{dL}$.

${ }^{\mathrm{e}}$ The NNT refers the number of patients who need to receive treatment with a NOAC to prevent one additional bad outcome.

with aspirin (7.8 vs. $12.4 \%$; HR: $0.63,95 \%$ CI: $0.43-0.94) .{ }^{11}$ Therefore, despite the neutral results of NAVIGATE ESUS and RE-SPECT ESUS, there is a possibility that NOACs may provide favorable efficacy and safety profiles in the prevention of recurrent stroke in particular subgroups of stroke survivors enrolled in these trials, although further research is needed.

It is also important to note that several factors, such as dosing or the heterogeneous etiology of ESUS, could have affected outcomes in these trials. Considering that the standard dose of rivaroxaban for stroke prevention in patients with $\mathrm{AF}$ is $20 \mathrm{mg}$, it is possible that the rivaroxaban dose of $15 \mathrm{mg}$ used in NAVIGATE ESUS was not high enough to achieve the maximum therapeutic effect. In addition, not all potential embolic sources of ESUS, such as covert AF, atrial cardiopathy, left ventricular disease, aortic and non-stenotic carotid atherosclerosis, patent foramen ovale, and cancer, respond equally to NOACs. ${ }^{119} \mathrm{~A}$ recent analysis demonstrated that there is a major overlap of potential embolic sources in stroke survivors with ESUS, which may explain the neutral results of the NAVIGATE ESUS and RE-SPECT ESUS trials. ${ }^{19}$ Among all potential embolic sources, patients with AF had the highest risk of stroke recurrence, highlighting the need to identify these patients early. ${ }^{119}$ In the NAVIGATE ESUS trial, $3 \%$ of patients were found to have AF during the course of the study. ${ }^{10}$ Cardiac rhythm monitoring was performed prior to randomization to exclude patients with $\mathrm{AF}$, but the extent of screening for AF was not specified, other than as a minimal requirement. ${ }^{10}$ Despite attempts to exclude $\mathrm{AF}$ in the NAVIGATE and RE-SPECT ESUS trials, which may be effective in the short term, patients with relatively infrequent AF may suffer $\mathrm{AF}$ recurrences in the long term and then derive benefit from NOACs. Ongoing trials are investigating intensified monitoring for AF in patients with ESUS with the aim to identify predictors of covert AF. ${ }^{119,121}$ However, covert AF now seems to be a less important source of ESUS than originally thought. ${ }^{122}$

\section{Evidence for NOACs in Atherosclerotic Stroke Prevention}

The use of a NOAC combined with an antiplatelet agent has recently been studied in the secondary prevention of $\mathrm{CV}$ events, including stroke, in patients with chronic CV disease. ${ }^{27}$ The COMPASS trial in patients with atherosclerotic vascular disease demonstrated that the combination of rivaroxaban $2.5 \mathrm{mg}$ twice daily plus aspirin, but not rivaroxaban $5 \mathrm{mg}$ twice daily alone, was more effective than aspirin alone in reducing the risk of MACE, defined as CV death, stroke, or myocardial infarction. ${ }^{27}$ Rivaroxaban $2.5 \mathrm{mg}$ twice daily plus aspirin was associated with a relative risk reduction of MACE of $24 \%$ versus aspirin alone (HR: $0.76,95 \% \mathrm{CI}: 0.66-0.86 ; p<0.001$ ) and an absolute risk reduction of $1.3 \%$, corresponding to a number needed to treat of 77. In contrast, monotherapy with rivaroxaban $5 \mathrm{mg}$ twice daily did not significantly reduce MACE compared with aspirin (HR: 0.90, 95\% CI: 0.79-1.03; $p=0.12) .{ }^{27}$ While the rate of major bleeding was higher with the combination therapy than with aspirin alone, there was no difference in the rates of fatal bleeding or ICH between the two groups. ${ }^{27}$ Interestingly, the outcome of MACE was driven by a $42 \%$ reduction in the risk of stroke and an absolute 

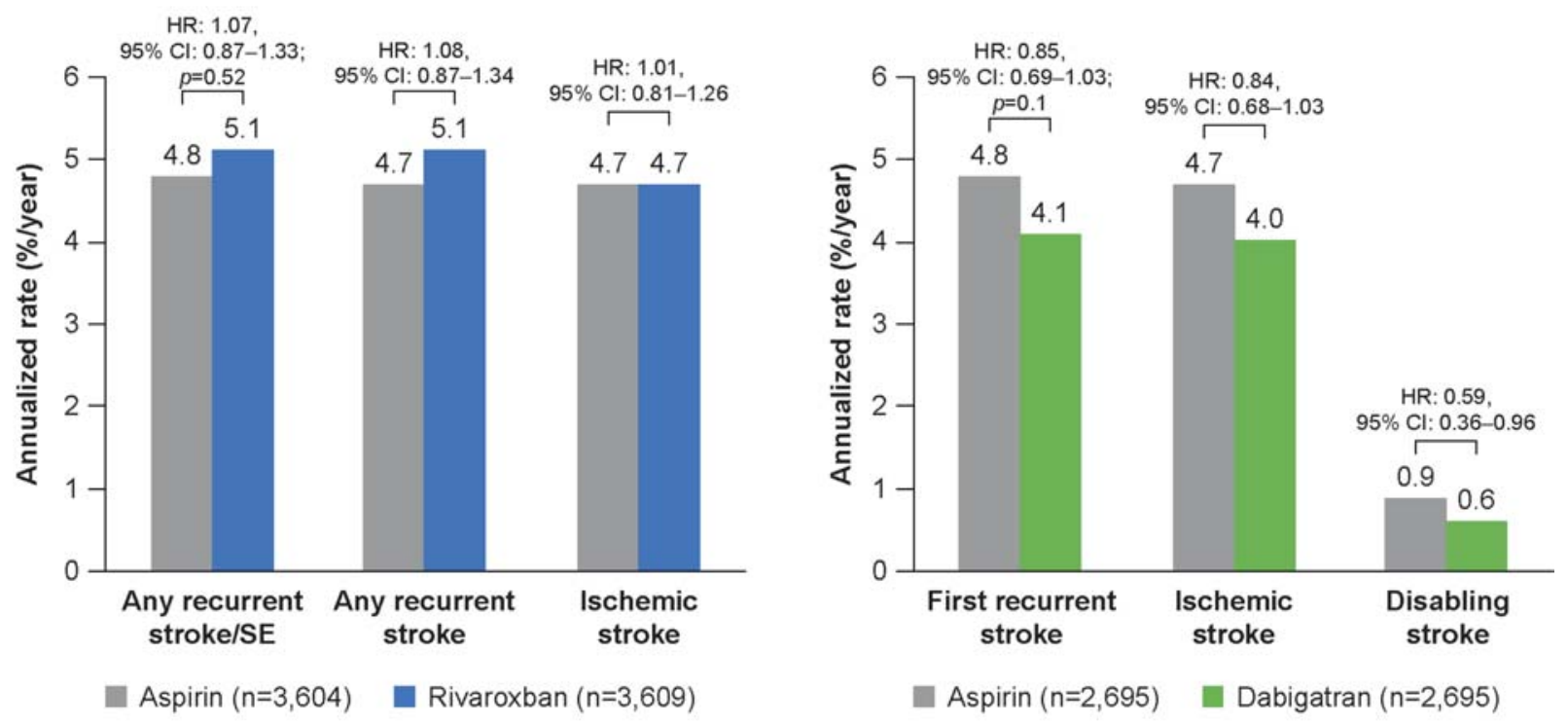

COMPASS

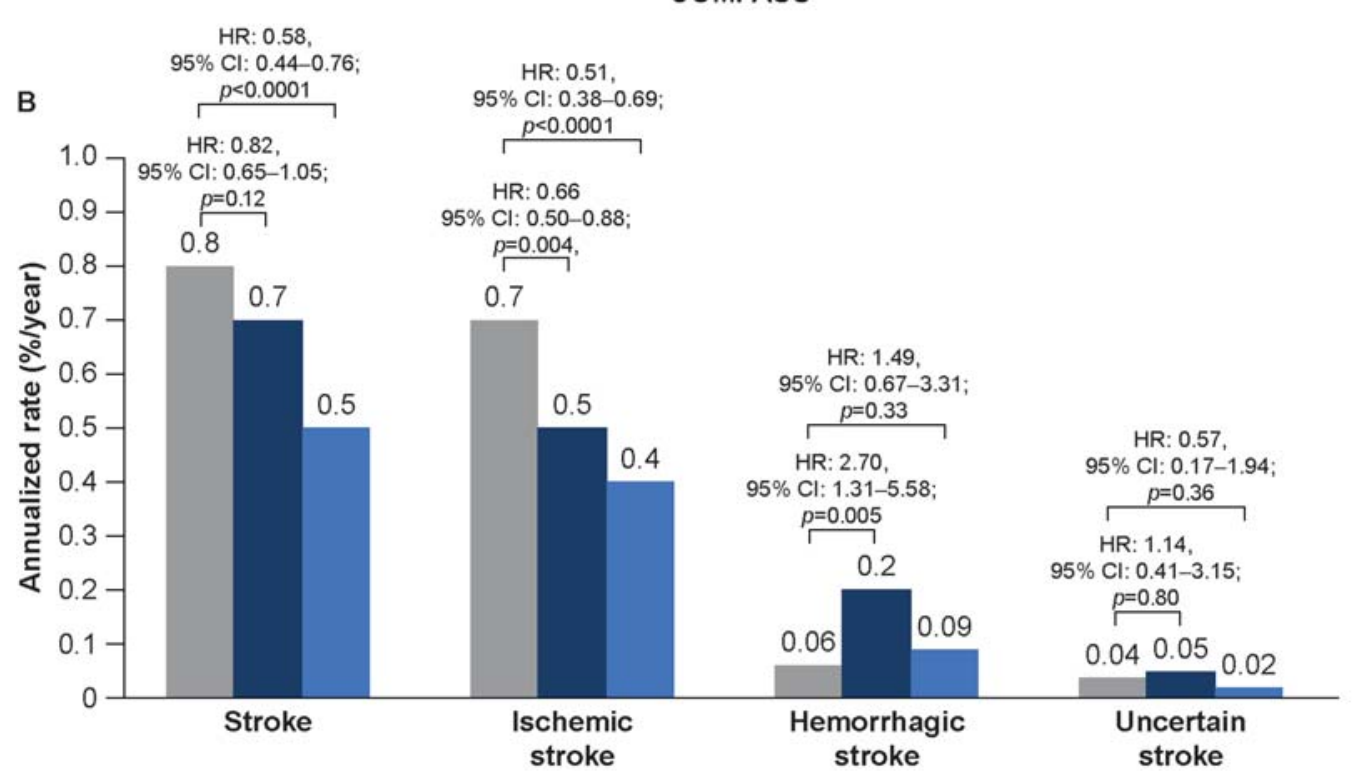

Aspirin $(n=9,126) \quad$ Rivaroxban 5 mg bid $(n=9,117)$

Rivaroxban $2.5 \mathrm{mg}$ bid plus aspirin $(n=9,152)$

Fig. 6 Stroke outcomes in the NAVIGATE ESUS and RE-SPECT ESUS trials ${ }^{10,11}$ (A) and in the COMPASS trial ${ }^{123}$ (B). bid, twice daily; Cl, confidence interval; HR, hazard ratio; SE, systemic embolism.

risk reduction of $0.7 \%$, corresponding to a number needed to treat of 143 (HR: $0.58,95 \% \mathrm{CI}: 0.44-0.76 ; p<0.0001$; - Fig. 6B). ${ }^{27}$ A recent subanalysis of the COMPASS data showed that this reduction was consistent in patients with coronary artery disease or peripheral artery disease at high risk of stroke, such as those with a previous stroke or those with diabetes. ${ }^{123}$ This analysis further demonstrated that the beneficial effect of rivaroxaban $2.5 \mathrm{mg}$ twice daily plus aspirin in stroke prevention was primarily driven by a $49 \%$ relative risk reduction in ischemic stroke (HR: $0.51,95 \% \mathrm{CI}$ : 0.38-0.69; $p<0.0001$ ), which was partially offset by a non-significant increase in hemorrhagic stroke. ${ }^{123}$ A secondary analysis of the
COMPASS trial investigating the effect of the combination therapy on different subtypes of ischemic stroke showed that rivaroxaban $2.5 \mathrm{mg}$ twice daily plus aspirin was associated with a significant reduction in cardioembolic stroke (HR: 0.40 , 95\% CI: $0.20-0.78 ; p=0.005$ ) and ESUS (HR: $0.30,95 \% \mathrm{CI}$ : $0.12-0.74 ; p=0.006$ ) compared with aspirin alone. ${ }^{124}$ No significant reductions were observed in patients with other subtypes of ischemic stroke. ${ }^{124}$ Based on these findings, it is likely that this, and other anticoagulant-antiplatelet combination therapies, will be investigated in randomized controlled trials in patients with ESUS and those with ESUS and atherosclerosis in the near future. 
The results of the COMPASS trial have led to the approval of rivaroxaban $2.5 \mathrm{mg}$ twice daily in combination with aspirin for the prevention of atherothrombotic events in patients with atherosclerotic vascular disease. ${ }^{108}$ Rivaroxaban is so far the only NOAC approved for this indication, and, although it is plausible that combination therapies with aspirin and other NOACs may also be associated with a beneficial effect, current evidence does not support this. Furthermore, other NOAC studies did not evaluate very low doses in combination with an antiplatelet. ${ }^{25,129}$

\section{Conclusion}

Stroke survivors with heart failure and CAD without and AF also have an increased risk of stroke compared with the general population. ${ }^{125,126}$ In COMMANDER HF, rivaroxaban $2.5 \mathrm{mg}$ twice daily added to antiplatelet therapy and standard heart failure therapy did not reduce the composite of death, stroke, or myocardial infarction compared with placebo in patients with heart failure and reduced ejection fraction, coronary artery disease, and without AF; however, this combination seemed to reduce the risk of stroke alone. $^{127}$ A posthoc analysis of COMMANDER HF demonstrated that the addition of rivaroxaban $2.5 \mathrm{mg}$ twice daily to background antiplatelet therapy reduced the risk of all-cause stroke or transient ischemic attack compared with placebo by $32 \%$ (HR: $0.68,95 \% \mathrm{CI}: 0.49-0.94 ; p=0.02$ ). ${ }^{128}$

\section{Conclusion}

In the past few years, new data have been published on the use of NOACs across the stroke spectrum, for the prevention of thromboembolic stroke, ESUS, and atherosclerotic stroke. While NOACs are an established treatment option in the prevention of thromboembolic stroke in patients with $\mathrm{AF}$, recent data suggest differential effects of NOACs in patients with comorbidities such as renal impairment or diabetes. In addition, the efficacy and safety of NOACs have been investigated in the prevention of recurrent stroke in patients with a recent history of ESUS. Even though the trials for rivaroxaban and dabigatran in ESUS were both neutral, subanalyses suggested a potential benefit of these NOACs in certain subgroups of patients with ESUS. Rivaroxaban $2.5 \mathrm{mg}$ twice daily combined with aspirin was also found to be effective in reducing the risk of stroke and other CV events in patients with chronic CV disease. While these new data contribute to our understanding of NOACs in the prevention of stroke across the stroke spectrum, more data are still needed to fill the remaining gaps in our knowledge.

\section{Funding}

This study was supported by Bayer.

\section{Conflict of Interest}

A.J.C. has received institutional grants and personal fees from Bayer AG, Boehringer Ingelheim, BMS, Daiichi Sankyo, and Pfizer, and personal fees from Abbott and Boston Scientific.
D.A. has received speaker and consultancy honoraria from Boehringer Ingelheim, BMS/Pfizer, MSD, Bayer Healthcare, and AstraZeneca, and research grants to the institution from Medtronic and BMS/Pfizer.

\section{Acknowledgments}

The authors would like to acknowledge Sarah Atkinson from Chameleon Communications International, who provided editorial assistance with the preparation of the manuscript, with funding from Bayer AG.

\section{References}

1 World Health Organization The top 10 causes of death. 2018. Accessed October 5, 2020 at: https://www.who.int/news-room/ fact-sheets/detail/the-top-10-causes-of-death

2 Feigin VL, Norrving B, Mensah GA. Global burden of stroke. Circ Res 2017;120(03):439-448

3 Andersen KK, Olsen TS, Dehlendorff C, Kammersgaard LP. Hemorrhagic and ischemic strokes compared: stroke severity, mortality, and risk factors. Stroke 2009;40(06):2068-2072

4 Hart RG, Diener HC, Coutts SB, et al; Cryptogenic Stroke/ESUS International Working Group. Embolic strokes of undetermined source: the case for a new clinical construct. Lancet Neurol 2014; 13(04):429-438

5 Tomek A. Embolic stroke of undetermined source (ESUS). CNS 2018;4:92-97

6 Hart RG, Catanese L, Perera KS, Ntaios G, Connolly SJ. Embolic stroke of undetermined source: a systematic review and clinical update. Stroke 2017;48(04):867-872

7 Kernan WN, Ovbiagele B, Black HR, et al; American Heart Association Stroke Council, Council on Cardiovascular and Stroke Nursing, Council on Clinical Cardiology, and Council on Peripheral Vascular Disease. Guidelines for the prevention of stroke in patients with stroke and transient ischemic attack: a guideline for healthcare professionals from the American Heart Association/American Stroke Association. Stroke 2014;45(07):2160-2236

8 Albers GW, Amarenco P, Easton JD, Sacco RL, Teal P. Antithrombotic and thrombolytic therapy for ischemic stroke: American College of Chest Physicians Evidence-Based Clinical Practice Guidelines (8th Edition). Chest 2008;133(06):630S6695

9 Lansberg MG, O'Donnell MJ, Khatri P, et al. Antithrombotic and thrombolytic therapy for ischemic stroke: Antithrombotic Therapy and Prevention of Thrombosis, 9th ed: American College of Chest Physicians Evidence-Based Clinical Practice Guidelines. Chest 2012;141(2, Suppl):e601S-e636S

10 Hart RG, Sharma M, Mundl H, et al; NAVIGATE ESUS Investigators. Rivaroxaban for stroke prevention after embolic stroke of undetermined source. N Engl J Med 2018;378(23):2191-2201

11 Diener HC, Sacco RL, Easton JD, et al; RE-SPECT ESUS Steering Committee and Investigators. Dabigatran for prevention of stroke after embolic stroke of undetermined source. N Engl J Med 2019;380(20):1906-1917

12 Topcuoglu MA, Liu L, Kim DE, Gurol ME. Updates on prevention of cardioembolic strokes. J Stroke 2018;20(02):180-196

13 LaMori JC, Mody SH, Gross HJ, et al. Burden of comorbidities among patients with atrial fibrillation. Ther Adv Cardiovasc Dis 2013;7(02):53-62

14 Wolf PA, Abbott RD, Kannel WB. Atrial fibrillation as an independent risk factor for stroke: the Framingham Study. Stroke 1991;22(08):983-988

15 Kirchhof P, Benussi S, Kotecha D, et al; ESC Scientific Document Group. 2016 ESC guidelines for the management of atrial fibrillation developed in collaboration with EACTS. Eur Heart J 2016; 37(38):2893-2962 
16 Steffel J, Verhamme P, Potpara TS, et al; ESC Scientific Document Group. The 2018 European Heart Rhythm Association Practical Guide on the use of non-vitamin Kantagonist oral anticoagulants in patients with atrial fibrillation. Eur Heart J 2018;39(16): 1330-1393

17 Adams HP Jr. Secondary prevention of atherothrombotic events after ischemic stroke. Mayo Clin Proc 2009;84(01):43-51

18 Aboyans V, Ricco JB, Bartelink MEL, et al. Editor's Choice - 2017 ESC Guidelines on the Diagnosis and Treatment of Peripheral Arterial Diseases, in collaboration with the European Society for Vascular Surgery (ESVS). Eur J Vasc Endovasc Surg 2018;55(03): 305-368

19 Knuuti J, Wijns W, Saraste A, et al; ESC Scientific Document Group. 2019 ESC guidelines for the diagnosis and management of chronic coronary syndromes. Eur Heart J 2020;41(03):407-477

20 Smith SC Jr, Benjamin EJ, Bonow RO, et al; World Heart Federation and the Preventive Cardiovascular Nurses Association. AHA/ ACCF secondary prevention and risk reduction therapy for patients with coronary and other atherosclerotic vascular disease: 2011 update: a guideline from the American Heart Association and American College of Cardiology Foundation. Circulation 2011;124(22):2458-2473

21 Roffi M, Patrono C, Collet JP, et al; ESC Scientific Document Group. 2015 ESC guidelines for the management of acute coronary syndromes in patients presenting without persistent STsegment elevation: Task Force for the Management of Acute Coronary Syndromes in Patients Presenting without Persistent ST-Segment Elevation of the European Society of Cardiology (ESC). Eur Heart J 2016;37(03):267-315

22 Hurlen M, Abdelnoor M, Smith P, Erikssen J, Arnesen H. Warfarin, aspirin, or both after myocardial infarction. N Engl J Med 2002; 347(13):969-974

23 van Es RF, Jonker JJ, Verheugt FW, Deckers JW, Grobbee DEAntithrombotics in the Secondary Prevention of Events in Coronary Thrombosis-2 (ASPECT-2) Research Group. Aspirin and coumadin after acute coronary syndromes (the ASPECT-2 study): a randomised controlled trial. Lancet 2002;360(9327):109-113

24 Alexander JH, Lopes RD, James S, et al; APPRAISE-2 Investigators. Apixaban with antiplatelet therapy after acute coronary syndrome. N Engl J Med 2011;365(08):699-708

25 Oldgren J, Budaj A, Granger CB, et al; RE-DEEM Investigators. Dabigatran vs. placebo in patients with acute coronary syndromes on dual antiplatelet therapy: a randomized, doubleblind, phase II trial. Eur Heart J 2011;32(22):2781-2789

26 Mega JL, Braunwald E, Wiviott SD, et al; ATLAS ACS 2-TIMI 51 Investigators. Rivaroxaban in patients with a recent acute coronary syndrome. N Engl J Med 2012;366(01):9-19

27 Eikelboom JW, Connolly SJ, Bosch J, et al; COMPASS Investigators. Rivaroxaban with or without aspirin in stable cardiovascular disease. N Engl J Med 2017;377(14):1319-1330

28 Go AS, Fang MC, Udaltsova N, et al; ATRIA Study Investigators. Impact of proteinuria and glomerular filtration rate on risk of thromboembolism in atrial fibrillation: the Anticoagulation and Risk Factors in Atrial Fibrillation (ATRIA) study. Circulation 2009; 119(10):1363-1369

29 Connolly SJ, Ezekowitz MD, Yusuf S, et al; RE-LY Steering Committee and Investigators. Dabigatran versus warfarin in patients with atrial fibrillation. N Engl J Med 2009;361(12): 1139-1151

30 Patel MR, Mahaffey KW, Garg J, et al; ROCKET AF Investigators. Rivaroxaban versus warfarin in nonvalvular atrial fibrillation. N Engl J Med 2011;365(10):883-891

31 Granger CB, Alexander JH, McMurray JJ, et al; ARISTOTLE Committees and Investigators. Apixaban versus warfarin in patients with atrial fibrillation. N Engl J Med 2011;365(11):981-992

32 Giugliano RP, Ruff CT, Braunwald E, et al; ENGAGE AF-TIMI 48 Investigators. Edoxaban versus warfarin in patients with atrial fibrillation. N Engl J Med 2013;369(22):2093-2104
33 Ruff CT, Giugliano RP, Braunwald E, et al. Comparison of the efficacy and safety of new oral anticoagulants with warfarin in patients with atrial fibrillation: a meta-analysis of randomised trials. Lancet 2014;383(9921):955-962

34 Coleman CI, Peacock WF, Bunz TJ, Alberts MJ. Effectiveness and safety of apixaban, dabigatran, and rivaroxaban versus warfarin in patients with nonvalvular atrial fibrillation and previous stroke or transient ischemic attack. Stroke 2017;48(08):2142-2149

35 Camm AJ, Amarenco P, Haas S, et al; XANTUS Investigators. XANTUS: a real-world, prospective, observational study of patients treated with rivaroxaban for stroke prevention in atrial fibrillation. Eur Heart J 2016;37(14):1145-1153

36 Coleman CI, Briere JB, Fauchier L, et al. Meta-analysis of realworld evidence comparing non-vitamin $\mathrm{K}$ antagonist oral anticoagulants with vitamin $\mathrm{K}$ antagonists for the treatment of patients with non-valvular atrial fibrillation. J Mark Access Health Policy 2019;7(01):1574541

37 Ntaios G, Papavasileiou V, Makaritsis K, Vemmos K, Michel P, Lip GYH. Real-world setting comparison of non-vitamin-K antagonist oral anticoagulants versus vitamin-K antagonists for stroke prevention in atrial fibrillation: a systematic review and metaanalysis. Stroke 2017;48(09):2494-2503

38 Yao X, Shah ND, Sangaralingham LR, Gersh BJ, Noseworthy PA. Non-vitamin $\mathrm{K}$ antagonist oral anticoagulant dosing in patients with atrial fibrillation and renal dysfunction. J Am Coll Cardiol 2017;69(23):2779-2790

39 Kumar S, Lim E, Covic A, , et al. Anticoagulation in Concomitant Chronic Kidney Disease and Atrial Fibrillation: JACC Review Topic of the Week. J Am Coll Cardiol 2019;74(17):2204-2215

40 Potpara TS, Ferro CJ, Lip GYH. Use of oral anticoagulants in patients with atrial fibrillation and renal dysfunction. Nat Rev Nephrol 2018;14(05):337-351

41 Olesen JB, Lip GYH, Kamper AL, et al. Stroke and bleeding in atrial fibrillation with chronic kidney disease. N Engl J Med 2012;367 (07):625-635

42 Yao X, Tangri N, Gersh BJ, et al. Renal outcomes in anticoagulated patients with atrial fibrillation. J Am Coll Cardiol 2017;70(21): 2621-2632

43 Fox KAA, Piccini JP, Wojdyla D, et al. Prevention of stroke and systemic embolism with rivaroxaban compared with warfarin in patients with non-valvular atrial fibrillation and moderate renal impairment. Eur Heart J 2011;32(19):2387-2394

44 Hijazi Z, Hohnloser SH, Oldgren J, et al. Efficacy and safety of dabigatran compared with warfarin in relation to baseline renal function in patients with atrial fibrillation: a RE-LY (Randomized Evaluation of Long-term Anticoagulation Therapy) trial analysis. Circulation 2014;129(09):961-970

45 Hohnloser SH, Hijazi Z, Thomas L, et al. Efficacy of apixaban when compared with warfarin in relation to renal function in patients with atrial fibrillation: insights from the ARISTOTLE trial. Eur Heart J 2012;33(22):2821-2830

46 Bohula EA, Giugliano RP, Ruff CT, et al. Impact of renal function on outcomes with edoxaban in the ENGAGE AF-TIMI 48 trial. Circulation 2016;134(01):24-36

47 Weir MR, Berger JS, Ashton V, et al. Impact of renal function on ischemic stroke and major bleeding rates in nonvalvular atrial fibrillation patients treated with warfarin or rivaroxaban: a retrospective cohort study using real-world evidence. Curr Med Res Opin 2017;33(10):1891-1900

48 Coleman CI, Martinez BK, Turpie AGG, Sood N, Bunz TJ, Kreutz R. Effectiveness and safety of rivaroxaban vs. warfarin in patients with nonvalvular atrial fibrillation and moderate-to-severe chronic kidney disease. Blood 2017;130:2393

49 Bonnemeier H, Huelsebeck M, Kloss S. Comparative effectiveness of rivaroxaban versus a vitamin $\mathrm{K}$ antagonist in patients with renal impairment treated for non-valvular atrial fibrillation in Germany - a retrospective cohort study. Int J Cardiol Heart Vasc 2019;23:100367 
50 Bonnemeier H, Kreutz R, Kloss S, Enders D, Häckl D, Schmedt NComparative safety and effectiveness of non-vitamin-K oral anticoagulants vs phenprocoumon in patients with non-valvular atrial fibrillation and renal disease - results from the RELOADED study Paper presented at: 5th European Stroke Organisation Conference, Milan, Italy, May 22-24,2019 Abstract AS25-066. Accessed October 5, 2020 at: https://journals.sagepub.com/toc/esoa/4/1_suppl

51 Chan KE, Edelman ER, Wenger JB, Thadhani RI, Maddux FW. Dabigatran and rivaroxaban use in atrial fibrillation patients on hemodialysis. Circulation 2015;131(11):972-979

52 Stanton BE, Barasch NS, Tellor KB. Comparison of the safety and effectiveness of apixaban versus warfarin in patients with severe renal impairment. Pharmacotherapy 2017;37(04):412-419

53 Siontis KC, Zhang X, Eckard A, et al. Outcomes associated with apixaban use in end-stage kidney disease patients with atrial fibrillation in the United States. Circulation 2018;138(15):15191529

54 Coleman CI, Kreutz R, Sood NA, et al. Rivaroxaban versus warfarin in patients with nonvalvular atrial fibrillation and severe kidney disease or undergoing hemodialysis. Am J Med 2019;132 (09):1078-1083

55 Chang $\mathrm{SH}, \mathrm{Wu} \mathrm{CV}$, Yeh YH, et al. Efficacy and safety of oral anticoagulants in patients with atrial fibrillation and stages 4 or 5 chronic kidney disease. Am J Med 2019;132(11):1335-1343.e6

56 Marti HP, Serebruany V, Atar D. Challenging anticoagulation in advanced renal failure. Am J Med 2019;132(11):1258-1259

57 Janssen Pharmaceuticals Inc. Xarelto (rivaroxaban): Prescribing Information. 2020. Accessed October 5, 2020 at: http://www. janssenlabels.com/package-insert/product-monograph/prescribing-information/XARELTO-pi.pdf

58 Boehringer Ingelheim Pharmaceuticals Inc. Pradaxa ${ }^{\circledR}$ (dabigatran etexilate): Prescribing Information. 2020. Accessed October 5, 2020 at: http://bidocs.boehringer-ingelheim.com/BIWebAccess/ ViewServlet.ser?docBase $=$ renetnt\&folderPath $=/$ Prescribing\% 20Information/PIs/Pradaxa/Pradaxa.pdf

59 Daiichi Sankyo Inc. Savaysa ${ }^{\circledR}$ (edoxaban): Prescribing information. 2020. Accessed October 5, 2020 at: http://dsi.com/prescribing-information-portlet/getPIContent? productName $=$ Savaysa\&inline $=$ true

60 Bristol-Myers Squibb Company Pfizer Inc. Eliquis ${ }^{\circledR}$ (apixaban): Prescribing Information. 2019. Accessed October 5, 2020 at: http://packageinserts.bms.com/pi/pi_eliquis.pdf

61 Pokorney SDRENAL-AF: Apixaban vs. warfarin for stroke prevention in patients with end stage renal disease on hemodialysis and AFib. 2019. Accessed February 4, 2020 at: https://www.acc. org/education-and-meetings/image-and-slide-gallery/mediadetail?id=469e5bd88fff4d2bb8ec183e71521637

62 Atrial Fibrillation Network Bristol-Myers Squibb, Pfizer Compare apixaban and vitamin-K antagonists in patients with atrial fibrillation (AF) and end-stage kidney disease (ESKD) (AXADIA). 2019. Accessed October 5, 2020 at: https://clinicaltrials.gov/ct2/ show/NCT02933697

63 St Michael's Hospital, Canadian Institutes of Health Research Strategies for the management of atrial fibrillation in patients receiving hemodialysis (SAFE-HD). 2019. Accessed October 5, 2020 at: https://clinicaltrials.gov/ct2/show/NCT03987711

64 Wheeler DS, Giugliano RP, Rangaswami J. Anticoagulation-related nephropathy. J Thromb Haemost 2016;14(03):461-467

65 Brodsky S, Eikelboom J, Hebert LA. Anticoagulant-related nephropathy. J Am Soc Nephrol 2018;29(12):2787-2793

66 Posch F, Ay C, Stöger H, Kreutz R, Beyer-Westendorf J. Exposure to vitamin $\mathrm{k}$ antagonists and kidney function decline in patients with atrial fibrillation and chronic kidney disease. Res Pract Thromb Haemost 2019;3(02):207-216

67 Peeters FECM, Dudink EAMP, Kimenai DM, et al. Vitamin K antagonists, non-vitamin $\mathrm{K}$ antagonist oral anticoagulants, and vascular calcification in patients with atrial fibrillation. TH Open 2018;2(04):e391-e398
68 Di Lullo L, Ronco C, Cozzolino M, et al. Non-vitamin K-dependent oral anticoagulants (NOACs) in chronic kidney disease patients with atrial fibrillation. Thromb Res 2017;155:38-47

69 Brodsky SV, Nadasdy T, Rovin BH, et al. Warfarin-related nephropathy occurs in patients with and without chronic kidney disease and is associated with an increased mortality rate. Kidney Int 2011;80(02):181-189

70 Ryan M, Ware K, Qamri Z, et al. Warfarin-related nephropathy is the tip of the iceberg: direct thrombin inhibitor dabigatran induces glomerular hemorrhage with acute kidney injury in rats. Nephrol Dial Transplant 2014;29(12):2228-2234

71 van Gorp RH, Schurgers LJ. New insights into the pros and cons of the clinical use of vitamin $\mathrm{K}$ antagonists (VKAs) versus direct oral anticoagulants (DOACs). Nutrients 2015;7(11): 9538-9557

72 de Aquino Moura KB, Behrens PMP, Pirolli R, et al. Anticoagulantrelated nephropathy: systematic review and meta-analysis. Clin Kidney J 2019;12(03):400-407

73 Brodsky SV, Mhaskar NS, Thiruveedi S, et al. Acute kidney injury aggravated by treatment initiation with apixaban: another twist of anticoagulant-related nephropathy. Kidney Res Clin Pract 2017;36(04):387-392

74 Shin JI, Luo S, Alexander GC, et al. Direct oral anticoagulants and risk of acute kidney injury in patients with atrial fibrillation. J Am Coll Cardiol 2018;71(02):251-252

75 Chan YH, Yeh YH, See LC, et al. Acute kidney injury in Asians with atrial fibrillation treated with dabigatran or warfarin. J Am Coll Cardiol 2016;68(21):2272-2283

76 Chan YH, Yeh YH, Hsieh MY, et al. The risk of acute kidney injury in Asians treated with apixaban, rivaroxaban, dabigatran, or warfarin for non-valvular atrial fibrillation: a nationwide cohort study in Taiwan. Int J Cardiol 2018;265:83-89

77 Klil-Drori AJ, Azoulay L, Nie R, Renoux C, Nessim SJ, Filion KB. Comparative risk of acute kidney injury with oral anticoagulant use among patients with nonvalvular atrial fibrillation. Blood 2017;130:700

78 Coleman CI, Kreutz R, Sood N, et al. Rivaroxaban's impact on renal decline in patients with nonvalvular atrial fibrillation: a US MarketScan claims database analysis. Clin Appl Thromb Hemost 2019;25. Doi: 1076029619868535

79 Bonnemeier H, Kreutz R, Kloss S, Enders D, Häckl D, Schmedt N Comparative safety and effectiveness of non-vitamin-K oral anticoagulants vs phenprocoumon in patients with non-valvular atrial fibrillation and diabetes - results from the RELOADED study. Paper presented at: 5th European Stroke Organisation Conference. Milan, Italy, 2224 May 2019, AS25-069. Accessed October 5, 2020 at: https://journals.sagepub.com/toc/esoa/4/1_suppl

80 Vaitsiakhovich T, Coleman CI, Kleinjung F, et al. Worsening of renal function in atrial fibrillation patients with stage 3 or 4 chronic kidney disease treated with warfarin or rivaroxaban - evidence from the real-world CALLIPER study in the US claims. European Society of Cardiology Congress Paris, France, 31 August-5 September 2019, Poster P4746. Accessed October 5, 2020 at: https:// academic.oup.com/eurheartj/article-abstract/40/Supplement_1/ ehz745.1122/5596296? redirectedFrom=fulltext

81 Hernandez AV, Bradley G, Khan M, et al. Rivaroxaban vs. warfarin and renal outcomes in non-valvular atrial fibrillation patients with diabetes. Eur Heart J Qual Care Clin Outcomes 2020;6(04): 301-307

82 GWT-TUD GmbH ClinStat GmbH Factor XA - inhibition in renal patients with non-valvular atrial fibrillation - observational registry (XARENO). 2019. Accessed October 5, 2020 at: https:// clinicaltrials.gov/ct2/show/NCT02663076

83 January CT, Wann LS, Calkins H, et al. 2019 AHA/ACC/HRS Focused Update of the 2014 AHA/ACC/HRS Guideline for the Management of Patients With Atrial Fibrillation: a report of the American College of Cardiology/American Heart Association Task Force on Clinical Practice Guidelines and the Heart Rhythm 
Society in collaboration with the Society of Thoracic Surgeons. Circulation 2019;140(02):e125-e151

84 De Sensi F, De Potter T, Cresti A, Severi S, Breithardt G. Atrial fibrillation in patients with diabetes: molecular mechanisms and therapeutic perspectives. Cardiovasc Diagn Ther 2015;5 (05):364-373

85 Bhatt DL, Steg PG, Ohman EM, et al; REACH Registry Investigators. International prevalence, recognition, and treatment of cardiovascular risk factors in outpatients with atherothrombosis. JAMA 2006;295(02):180-189

86 Stroke Risk in Atrial Fibrillation Working Group. Independent predictors of stroke in patients with atrial fibrillation: a systematic review. Neurology 2007;69(06):546-554

87 Olesen JB, Fauchier L, Lane DA, Taillandier S, Lip GYH. Risk factors for stroke and thromboembolism in relation to age among patients with atrial fibrillation: the Loire Valley Atrial Fibrillation Project. Chest 2012;141(01):147-153

88 Fangel MV, Nielsen PB, Larsen TB, et al. Type 1 versus type 2 diabetes and thromboembolic risk in patients with atrial fibrillation: a Danish nationwide cohort study. Int J Cardiol 2018;268:137-142

89 Plitt A, McGuire DK, Giugliano RP. Atrial fibrillation, type 2 diabetes, and non-vitamin $\mathrm{K}$ antagonist oral anticoagulants: a review. JAMA Cardiol 2017;2(04):442-448

90 Wang A, Green JB, Halperin JL, Piccini JP Sr. Atrial fibrillation and diabetes mellitus: JACC review topic of the week. J Am Coll Cardiol 2019;74(08):1107-1115

91 American Diabetes Association. 10. Cardiovascular disease and risk management: standards of medical care in diabetes-2019. Diabetes Care 2019;42(Suppl 1):S103-S123

92 Koye DN, Magliano DJ, Nelson RG, Pavkov ME. The global epidemiology of diabetes and kidney disease. Adv Chronic Kidney Dis 2018;25(02):121-132

93 Cavanaugh KL. Diabetes management issues for patients with chronic kidney disease. Clin Diabetes 2007;25:90-97

94 Coresh J, Astor BC, Greene T, Eknoyan G, Levey AS. Prevalence of chronic kidney disease and decreased kidney function in the adult US population: Third National Health and Nutrition Examination Survey. Am J Kidney Dis 2003;41(01):1-12

95 Middleton RJ, Foley RN, Hegarty J, et al. The unrecognized prevalence of chronic kidney disease in diabetes. Nephrol Dial Transplant 2006;21(01):88-92

96 Hertig A, Rondeau E. Role of the coagulation/fibrinolysis system in fibrin-associated glomerular injury. J Am Soc Nephrol 2004; 15 (04):844-853

97 Farquhar A, MacDonald MK, Ireland JT. The role of fibrin deposition in diabetic glomerulosclerosis: a light, electron and immunofluorescence microscopy study. J Clin Pathol 1972;25(08): 657-667

98 Tanaka M, Arai H, Liu N, et al. Role of coagulation factor Xa and protease-activated receptor 2 in human mesangial cell proliferation. Kidney Int 2005;67(06):2123-2133

99 Sumi A, Yamanaka-Hanada N, Bai F, Makino T, Mizukami H, Ono $\mathrm{T}$. Roles of coagulation pathway and factor Xa in the progression of diabetic nephropathy in $\mathrm{db} / \mathrm{db}$ mice. Biol Pharm Bull 2011;34 (06):824-830

100 Amdur RL, Feldman HI, Gupta J, et al; CRIC Study Investigators. Inflammation and progression of CKD: the CRIC study. Clin J Am Soc Nephrol 2016;11(09):1546-1556

101 Afkarian M, Sachs MC, Kestenbaum B, et al. Kidney disease and increased mortality risk in type 2 diabetes. J Am Soc Nephrol 2013;24(02):302-308

102 Ezekowitz JA, Lewis BS, Lopes RD, et al. Clinical outcomes of patients with diabetes and atrial fibrillation treated with apixaban: results from the ARISTOTLE trial. Eur Heart J Cardiovasc Pharmacother 2015;1(02):86-94

103 Brambatti M, Darius H, Oldgren J, et al. Comparison of dabigatran versus warfarin in diabetic patients with atrial fibrillation: Results from the RE-LY trial. Int J Cardiol 2015;196:127-131
104 Bansilal S, Bloomgarden Z, Halperin JL, et al; ROCKET AF Steering Committee and Investigators. Efficacy and safety of rivaroxaban in patients with diabetes and nonvalvular atrial fibrillation: the Rivaroxaban Once-daily, Oral, Direct Factor Xa Inhibition Compared with Vitamin K Antagonism for Prevention of Stroke and Embolism Trial in Atrial Fibrillation (ROCKET AF Trial). Am Heart J 2015;170(04):675.e8-682.e8

105 Plitt A, Ruff CT, Goudev A, et al. Efficacy and safety of edoxaban in patients with diabetes mellitus in the ENGAGE AF-TIMI 48 trial. Int J Cardiol 2020;304:185-191

106 Coleman CI, Bunz TJ, Eriksson D, Meinecke AK, Sood NA. Effectiveness and safety of rivaroxaban vs warfarin in people with non-valvular atrial fibrillation and diabetes: an administrative claims database analysis. Diabet Med 2018;35(08):1105-1110

107 Baker WL, Beyer-Westendorf J, Bunz TJ, et al. Effectiveness and safety of rivaroxaban and warfarin for prevention of major adverse cardiovascular or limb events in patients with nonvalvular atrial fibrillation and type 2 diabetes. Diabetes Obes Metab 2019;21(09):2107-2114

108 Bayer AGXarelto ${ }^{\circledR}$ (rivaroxaban): summary of product characteristics. 2020. Accessed July 30, 2020 at: https://www.ema. europa.eu/documents/product-information/xarelto-epar-product-information_en.pdf

109 Bristol Myers Squibb Pfizer Eliquis ${ }^{\circledR}$ (apixaban): summary of product characteristics. 2020. Accessed July 30, 2020 at: http://www. ema.europa.eu/docs/en_GB/document_library/EPAR_-_Product_Information/human/002148/WC500107728.pdf

110 Boehringer Ingelheim International GmbH Pradaxa ${ }^{\circledR}$ (dabigatran etexilate): summary of product characteristics. 2020. Accessed September 8, 2020 at: http://www.ema.europa.eu/docs/en_GB/ document_library/EPAR_-_Product_Information/human/ 000829/WC500041059.pdf

111 Daiichi Sankyo Europe Gmb HLixiana ${ }^{\circledR}$ (edoxaban): summary of product characteristics. 2019. Accessed April 9, 2020 at: http:// www.ema.europa.eu/docs/en_GB/document_library/EPAR_-_Product_Information/human/002629/WC500189045.pdf

112 Steinberg BA, Shrader P, Thomas L, et al; ORBIT-AF Investigators and Patients. Off-label dosing of non-vitamin $\mathrm{K}$ antagonist oral anticoagulants and adverse outcomes: the ORBIT-AF II registry. J Am Coll Cardiol 2016;68(24):2597-2604

113 Steinberg BA, Shrader P, Pieper K, et al; Outcomes Registry for Better Informed Treatment of Atrial Fibrillation (ORBIT -AF) II Investigators. Frequency and outcomes of reduced dose nonvitamin $\mathrm{K}$ antagonist anticoagulants: results from ORBIT-AF II (The Outcomes Registry for Better Informed Treatment of Atrial Fibrillation II). J Am Heart Assoc 2018;7(04):e007633

114 Atar D, Grundvold I. On-label reduced doses of non-vitamin K anticoagulants prove safe and efficient; yet how to ensure the correct dose for the right patient? Eur Heart J 2019;40(19): 1501-1503

115 Lowres N, Giskes K, Hespe C, Freedman B. Reducing stroke risk in atrial fibrillation: adherence to guidelines has improved, but patient persistence with anticoagulant therapy remains suboptimal. Korean Circ J 2019;49(10):883-907

116 Geisler T, Poli S, Meisner C, et al. Apixaban for treatment of embolic stroke of undetermined source (ATTICUS randomized trial): rationale and study design. Int J Stroke 2017;12(09):985-990

117 Kamel H, Longstreth WT Jr, Tirschwell DL, et al. The AtRial Cardiopathy and Antithrombotic Drugs In prevention After cryptogenic stroke randomized trial: rationale and methods. Int J Stroke 2019;14(02):207-214

118 Healey JS, Gladstone DJ, Swaminathan B, et al. Recurrent stroke with rivaroxaban compared with aspirin according to predictors of atrial fibrillation: secondary analysis of the NAVIGATE ESUS randomized clinical trial. JAMA Neurol 2019;76(07):764-773

119 Ntaios G, Perlepe K, Lambrou D, et al. Prevalence and overlap of potential embolic sources in patients with embolic stroke of undetermined source. J Am Heart Assoc 2019;8(15):e012858 
120 University of Thessaly, University of Lausanne, University of Athens Prediction of AF in ESUS (AF-ESUS). 2019. Accessed October 5, 2020 at: https://clinicaltrials.gov/ct2/show/ NCT02766205

121 University of British Columbia Boehringer Ingelheim Thirty day heart monitoring for detection of atrial fibrillation among cryptogenic stroke patients (PROPhecy). 2019. Accessed October 5, 2020 at: https://clinicaltrials.gov/ct2/show/NCT03712865

122 Ntaios G. Embolic stroke of undetermined source: JACC review topic of the week. J Am Coll Cardiol 2020;75(03):333-340

123 Sharma M, Hart RG, Connolly SJ, et al. Stroke outcomes in the COMPASS trial. Circulation 2019;139(09):1134-1145

124 Alexander JH, Becker RC, Bhatt DL, et al; APPRAISE Steering Committee and Investigators. Apixaban, an oral, direct, selective factor Xa inhibitor, in combination with antiplatelet therapy after acute coronary syndrome: results of the Apixaban for Prevention of Acute Ischemic and Safety Events (APPRAISE) trial. Circulation 2009;119(22):2877-2885

125 Perera KS, Ng KKH, Nayar S, et al. Association between low-dose rivaroxaban with or without aspirin and ischemic stroke sub- types: a secondary analysis of the COMPASS trial. JAMA Neurol 2020;77(01):43-48

126 Ferreira JP, Girerd N, Gregson J, et al; High-Risk Myocardial Infarction Database Initiative. Stroke risk in patients with reduced ejection fraction after myocardial infarction without atrial fibrillation. J Am Coll Cardiol 2018;71(07):727-735

127 Melgaard L, Gorst-Rasmussen A, Lane DA, Rasmussen LH, Larsen $\mathrm{TB}$, Lip GYH. Assessment of the $\mathrm{CHA}_{2} \mathrm{DS}_{2}$-VASc score in predicting ischemic stroke, thromboembolism, and death in patients with heart failure with and without atrial fibrillation. JAMA 2015;314(10):1030-1038

128 Zannad F, Anker SD, Byra WM, et al; COMMANDER HF Investigators. Rivaroxaban in patients with heart failure, sinus rhythm, and coronary disease. N Engl J Med 2018;379(14): 1332-1342

129 Mehra MR, Vaduganathan M, Fu M, et al. A comprehensive analysis of the effects of rivaroxaban on stroke or transient ischaemic attack in patients with heart failure, coronary artery disease, and sinus rhythm: the COMMANDER HF trial. Eur Heart J 2019;40(44):3593-3602 